\title{
I ntegrating Google Glass into simulation-based training: experiences and future directions
}

\author{
Teresa Wu, Christian Dameff, Jeffrey Tully \\ Maricopa Medical Center, University of Arizona, College of Medicine-Phoenix, Phoenix, Arizona, USA \\ Correspondence: Teresa Wu. Address: 7012 E. Voltaire Avenue, Scottsdale, AZ 85254, USA. E-mail: \\ teresawumd@gmail.com
}

Received: March 3, 2014

Accepted: March 24, 2014

Online Published: April 18, 2014

DOI : $10.5430 / j b g c . v 4 n 2 p 49$

URL: http://dx.doi.org/10.5430/jbgc.v4n2p49

\section{Abstract}

Background: Education experts are starting to explore the potential uses of wearable technology and augmented reality in simulation-based training. In this article, we summarize our experiences with using Google Glass in simulation-based training and discuss potential future directions with this advanced technology.

Methods: Emergency medicine residents and medical students participated in a pilot study where each team captain was asked to wear Google Glass during 15 separate simulation-based training sessions. Video obtained from Google Glass was analyzed and utilized during debriefing sessions for the residents and medical students.

Results: We were able to successfully integrate Google Glass into simulation-based training and debriefing. During the analysis of each recording, observations were noted about the events that transpired and this data was used to provide instructional feedback to the residents and medical students for self-reflection and appraisal. Post-exercise surveys were conducted after each simulation session and all participants noted that Google Glass did not interfere with their simulation experience. Google Glass enabled the observers to analyze the team captain's primary visual focus during the entire simulation scenario and feedback was provided based on the data recorded.

Conclusions: Wearable technologies such as Google Glass can be successfully integrated into simulation-based training exercises without disrupting the learners' experience. Data obtained from this integration can be utilized to improve debriefing sessions and self-reflection. Future research is underway and required to evaluate other potential uses for wearable technology in simulation-based training.

\section{Key words}

Simulation-based training, Medical education, Google Glass, Wearable technology, Augmented reality

\section{I ntroduction}

In simulation-based training (SBT), practitioners and students are called upon to participate in a clinical scenario that mimics what they are likely to encounter in true clinical practice ${ }^{[1-3]}$. The practitioners and students are asked to work through the scenario in the same manner they would approach a similar case presenting in their department or office. In most simulation-based training exercises, both summative and formative feedback is provided to the participants based on information from educators actively observing and taking notes from the case, from direct observation of the critical 
actions of the case, from analysis of the end-point of the case, assessment of whether or not the team or individuals reached the end-point in the appropriate manner, and through observation of intent ${ }^{[4-6]}$.

Most simulation cases for medical education are designed around the concept of assessing critical actions or targeted responses from the learners ${ }^{[7]}$. Critical actions and target responses are usually objective and relatively easy to capture, measure, and discuss with SBT ${ }^{[8,9]}$. During the facilitated reflection session following the case, many facilitators will use video playback combined with verbal feedback to allow participants to view and reflect on their behaviors and critical responses from the case ${ }^{[10]}$. Although the benefits of video feedback are still currently being researched, studies have shown that participants enjoy watching and learning from their management of the scenario being assessed ${ }^{[11]}$. With video feedback, participants can see exactly how the scenario played out and compare reality with their perceptions of how things transpired. Critical actions can be highlighted with concrete examples taken from the scenario recordings, and participants receive a bird's eye view of the sequence of events as witnessed by the active and passive observers of the case $^{[12]}$.

The aspects of SBT that are harder to analyze are behavioral issues, focus points, and reactions during a clinical scenario ${ }^{[13]}$. Often times, the facilitator and content experts do not know what the participant is directing their attention to and whether or not they see the obvious abnormality in front of them. When observers are watching a simulation scenario, they are usually privy to the events of the case unfolding before them, but not the individual stimuli that prompt certain reactions and behaviors from the scenario participants. We postulate that it would be very useful to be able to visualize what the lead participant or team captain sees during a scenario, so that observers and participants can have more data to use in the analysis of their reactions and decisions.

Over the past few years, the concepts of wearable technology and augmented reality have begun receiving increased attention from medical providers and educators ${ }^{[14,15]}$. Wearable technology such as Google Glass offers a distinct portability and convenience over traditional computer workstations and often allows for integration of functionality and various applications during direct patient care. Augmented reality displays have the ability to provide additional information or direction directly into the wearer's point of view without the need to focus on ancillary displays ${ }^{[16,17]}$. The aim of this paper is to introduce and highlight our experience with wearable technology in simulation-based training and to discuss the feasibility of using wearable technology during simulation-based training scenarios for medical education.

\section{Methods}

This study took place during simulation-based training exercises utilized during standard simulation sessions for emergency medicine residents at a local academic teaching hospital. The study was granted exempt status by the Institutional Review Board (IRB) at the participating hospital. The emergency medicine residents who participated in the study are enrolled in a PGY 1-3 residency program at a Level 1 trauma center that cares for 65,000 patients annually. Forty-two emergency medicine residents and nine medical students participated in 15 simulation-based training sessions over the course of this study.

Participants of the study consented to wearing Google Glass (Google Inc; Mountain View, CA) during their simulationbased training exercise and the entire clinical scenario was recorded for subsequent review and analysis. The team captain was selected prior to the scenario and he/she wore Google glass for the entire case. Participants were blinded to the intent of the study and were instructed to participate in the simulation scenario in the standard manner by which previous simulation-based training exercises had been conducted for the residency program. All participants of the study had participated in at least two simulation-based training exercises prior to the study. Video was then recorded of each simulation scenario via Google Glass' camera for the entirety of each simulation. Videos by default were recorded in MP4 format and were downloaded from Google Glass through a standard micro-USB cable to a laptop running Mac OS X 
(v10.8; Apple Inc; Cupertino, CA). Each video was reviewed and analyzed by three independent observers following the conclusion of the simulation-based training exercises.

\section{Results}

Google Glass technology was integrated into 15 simulation-based training scenarios during the initial pilot testing (four scenarios each for PGY levels 1 through 3 and two involving medical students). The nine medical students enrolled in the study participated in three separate simulation-based training scenarios. During the analysis of each recording, observations were noted about the events that transpired and this data was used to provide instructional feedback to the residents and medical students for self-reflection and appraisal.

Participants were debriefed immediately after each simulation scenario to elicit their reactions to using wearable technology during the simulated cases. Prior to each scenario, video recording was activated on each Google Glass that was being worn during the case. Video recording was stopped at the conclusion of the case and prior to the debriefing sessions. Participants noted that they were able to wear Google Glass during the scenarios without any discomfort or hindrance of their abilities. All participants stated that they eventually forgot that they were wearing Google Glass at some point during the scenario and became completely focused on patient care and the events unfolding before them. There were no adjustments made to Google Glass once the scenarios began and no further programming was required until the cases officially ended. None of the participants noted any issues with viewing the patient, the cardiac monitor, the persons on their team, the equipment, or the case stimuli while wearing Google Glass. It is important to note that at our institution, all case stimuli are presented to the participants via a portable iPad so that the data can be reviewed and navigated at the patient's bedside. There were no technical issues with Google Glass recordings of any of the scenarios and both audio and visual input was adequate for review and analysis.

Each Google Glass recording was analyzed for objective variables that could be used to enhance both individual and team feedback and debriefing. Some general variables were analyzed such as how much time did the participant spend taking report from pre-hospital providers, how many times the participant looked at the cardiac monitor during the case, how many times did the participant look directly at the patient, how long did it take for the participant to verbalize an order after an abnormal vital sign was noted, how long did each participant spend reviewing stimuli for the case, did the participant watch the nurse as he/she administered medications, did the team captain oversee the procedures that were being performed, and did the participant require the use of reference tools such as the internet, smartphone applications, or resuscitation cards during the scenario (see the Table).

Table. Sample data obtained by reviewing Google Glass video of SBT cases

\begin{tabular}{lllll}
\hline Item & Med Students & PGY-1 & PGY-2 & PGY-3 \\
\hline Avg reaction time after abnormal monitor finding(s) & 9.66 & 15.19 & 10.6 & 4 \\
Avg time spent reviewing EKGs & $15(\mathrm{~N}=1)$ & $31(\mathrm{~N}=2)$ & $23(\mathrm{~N}=1)$ & $(\mathrm{N}=0)$ \\
Avg time spent reviewing Labs & $(\mathrm{N}=0)$ & $28(\mathrm{~N}=1)$ & $14(\mathrm{~N}=2)$ & $11(\mathrm{~N}=3)$ \\
Avg time spent reviewing Radiology & $8.66(\mathrm{~N}=3)$ & $30.66(\mathrm{~N}=6)$ & $22(\mathrm{~N}=1)$ & $(\mathrm{N}=0)$ \\
Avg time spent speaking with EMS & $23(\mathrm{~N}=1)$ & $57(\mathrm{~N}=2)$ & $16.5(\mathrm{~N}=4)$ & $20.3(\mathrm{~N}=3)$ \\
Observed medication administration & $50 \%(3 / 6)$ & $75 \%(9 / 12)$ & $46 \%(6 / 13)$ & $50 \%(7 / 14)$ \\
Observed procedures being performed & $100 \%(5 / 5)$ & $80 \%(4 / 5)$ & $83 \%(5 / 6)$ & $80 \%(8 / 10)$ \\
External clinical knowledge resource uses & $2($ Smartphones) & $2($ Pocket Cards) $)$ & $\mathrm{N} / \mathrm{A}$ & $2(\mathrm{Smartphones)}$ \\
Average monitor looks/min & $1.76(S D: 0.247)$ & $1.45(S D: 1.187)$ & $1.87(S D: 0.793)$ & $1.29(S D: 0.936)$ \\
Average patient looks/min & $2.56(S D: 0.447)$ & $3.94(S D: 1.55)$ & $3.96(S D: 0.244)$ & $5.47(S D 2.42)$ \\
\hline
\end{tabular}


For each scenario, observers also took note of events and behaviors that could be used for independent directed feedback to each participant. These events were discussed in either the formal reflection immediately following the simulation session or in subsequent discussions with the individual participants. Examples of such events include whether or not the team captain looked at, acknowledged, and incorporated all members of the team, did the team captain focus on the most vital component of the case when other attention-demanding tasks were being asked of him/her, did the team captain take too much or too little time reviewing and processing patient data, how long did the team captain listen to a team member before turning attention away to another task, did the team captain reassess and recap what has transpired during the case, did the team captain review the radiographic and laboratory results with the team, and did the team captain position him/herself in the appropriate position to be in charge of the case.

During the individualized debriefing, Google Glass recordings were also analyzed to comment on the participant's professionalism and interactions with the patient and family members during the case. Observers noted whether or not physical contact was made between the team captain and the patient and family members, who the team captain directed their attention to during discussions of the assessment or plan, how the team captain addressed concerns raised by the patient or family members, and if the team captain incorporated feedback or cues from other members of the team during these discussions. Google Glass enabled the observers to analyze the team captain's primary visual focus during the entire simulation scenario without disrupting the case.

\section{Discussion}

During most simulation-based training sessions, cameras are mounted strategically in the facility so that recordings can be made of the case from various angles ${ }^{[18]}$. To date, there has not been any literature published examining how wearable technologies can be employed to enhance the video recordings currently being used in modern day simulation-based training environments. By having the participants utilize wearable technology such as Google Glass, the facilitators and observers have the ability to see and analyze the simulation scenario with a completely novel and intimate vantage point. Adjuncts such as Google Glass provide the learners and educators with a perspective that hasn't been addressed or explored in current debriefing and reflection strategies.

Having the ability to examine and pinpoint what the participant is looking at during the scenario can truly enhance the debriefing process ${ }^{[19]}$. For example, in some of our scenarios, the pre-hospital providers gave very lengthy handoff summaries about the patient, even though immediate management was required based on the patient's clinical presentation and vital signs. With the Google Glass perspective, it was possible to teach the participants that they should adjust their primary focus to the patient while they are simultaneously listening to the pre-hospital report. Google Glass allowed observers and facilitators to discern whether or not the participant was looking at the important components of the patient presentation at the most ideal time points (i.e. patient's airway and respiratory status upon arrival, cardiac monitor once leads were placed onto the patient, primary and secondary survey findings during a trauma resuscitation, chest tube output in a suspected hemothorax, etc.)

From our analysis, we were able to obtain very detailed and useful information about each participant's practice style. These simulations were uniquely constructed to convey specific learning points to each training level and were not standardized across training levels, so while data provided by Google Glass in this study is not generalizable to larger trends, valuable information that could be tailored to specific student/resident and scenario feedback was provided. With Google Glass, we could see how long it took a participant to analyze a radiographic study prior to turning their attention elsewhere. We could observe how long it took a participant to acknowledge and act upon an abnormal vital sign being displayed on the cardiac monitor outside their immediate line of vision. Facilitators could also note whether the team captain was actively supervising critical procedures or instead directing their field of vision towards less important distractions, such as the nurses spiking a bag of fluids, or the ultrasound machine being plugged into the wall. Information 
such as this would be very helpful in places where simulation is being used to aid in resident and medical student remediation. Having the ability to analyze what the participant sees and focuses on can help with redirection and identification of knowledge translation issues ${ }^{[20-23]}$.

\section{Conclusions}

Wearable technologies such as Google Glass can be successfully integrated into simulation-based training exercises without disrupting the learners' experience. Data obtained from this integration can be utilized to improve debriefing sessions and self-reflection. Future research is underway and required to evaluate other potential uses for wearable technology in simulation-based training.

\section{Conflict of interests}

The authors declare that they have no conflict of interests.

\section{References}

[1] Aggarwal R, Darzi A. Technical-skills training in the 21st century. N Engl J Med. 2006; 355: 2695-6. PMid: 17182997. http://dx.doi.org/10.1056/NEJMe068179

[2] Small SD, Wuerz RC, Simon R, Shapiro N, Conn A, Setnik G. Demonstration of high- fidelity simulation team training for emergency medicine. Acad Emerg Med. 1999; 6: 312-23. PMid: 10230983. http://dx.doi.org/10.1111/j.1553-2712.1999.tb00395.x

[3] Satava RM. Historical review of surgical simulation--a personal perspective. World J Surg. 2008; 32: 141-8. PMid: 18097716. http://dx.doi.org/10.1007/s00268-007-9374-y

[4] Rosen MA, Weaver SJ, Lazzara EH, Salas E, Wu T, Silvestri S, et al. Tools for evaluating team performance in simulation-based training. J Emerg Trauma Shock. 2010; 3(4): 353-9. PMid: 21063558. http://dx.doi.org/10.4103/0974-2700.70746

[5] Ilgen JS, Sherbino J, Cook DA. Technology-enhanced simulation in emergency medicine: a systematic review and meta-analysis. Acad Emerg Med. 2013; 20: 117-27. PMid: 23406070. http://dx.doi.org/10.1111/acem.12076

[6] McLaughlin SA, Bond W, Promes S, Spillane L. The status of human simulation training in emergency medicine residency programs. Simul Healthc. 2006; 1 Spec no.: 18-21. PMid: 19088568. http://dx.doi.org/10.1097/01266021-200600010-00006

[7] Bond W, Kuhn G, Binstadt E, Quirk M, Wu T, Tews M, et al. The use of simulation in the development of individual cognitive expertise in emergency medicine.

[8] McLaughlin SA, Doezema D, Sklar DP. Human simulation in emergency medicine training: a model curriculum. Acad Emerg Med. 2002; 9: 1310-8. PMid: 12414487. http://dx.doi.org/10.1111/j.1553-2712.2002.tb01593.x

[9] McLaughlin S, Fitch MT, Goyal DG, Hayden E, Kauh CY, Laack TA, et al. Simulation in graduate medical education 2008: a review for emergency medicine. Acad Emerg Med. 2008; 15: 1117-29. PMid: 18638028. http://dx.doi.org/10.1111/j.1553-2712.2008.00188.x

[10] Ziv A, Ben-David S, Ziv M. Simulation based medical education: an opportunity to learn from errors. Medical teacher. 2005; 27(3): 193-199. PMid: 16011941. http://dx.doi.org/10.1080/01421590500126718

[11] Carbine DN, Finer NN, Knodel E, et al. Video record- ing as a means of evaluating neonatal resuscitation performance. Pediatrics. 2000; 106: 654-658. PMid: 11015505. http://dx.doi.org/10.1542/peds.106.4.654

[12] Binstadt ES, Walls RM, White BA, Nadel ES, Takayesu JK, Barker TD, et al. A comprehensive medical simulation education curriculum for emergency medicine residents. Annals of emergency medicine, 2007; 49(4): 495-504. PMid: 17161502. http://dx.doi.org/10.1016/j.annemergmed.2006.08.023

[13] Boulet JR, Murray D, Kras J, et al. Reliability and validity of a simulation-based acute care skills assessment for medical students and residents. Anesthesiology. 2003; 99: 1270-1280. PMid: 14639138. http://dx.doi.org/10.1097/00000542-200312000-00007

[14] Vozenilek J, Huff JS, Reznek M, Gordon JA. See one, do one, teach one: advanced technology in medical education. Acad Emerg Med. 2004; 11: 1149-54. PMid: 15528578. http://dx.doi.org/10.1111/j.1553-2712.2004.tb00698.x

[15] Reznek M, Harter P, Krummel T. Virtual reality and simulation: training the future emergency physician. Acad Emerg Med. 2002; 9: 78-87. PMid: 11772675. http://dx.doi.org/10.1111/j.1553-2712.2002.tb01172.x

[16] Azuma R, Baillot Y, Behringer R, Feiner S, Julier S, MacIntyre B. Recent advances in augmented reality. Computer Graphics and Applications, IEEE. 2001; 21: 34-47. http://dx.doi.org/10.1109/38.963459

[17] Azuma RT. A survey of augmented reality. Presence. 1997; 6: 355-85.

[18] McLaughlin S, Clarke S, Menon S, Noeller TP, Okuda Y, Smith MD, et al. Simulation in Emergency Medicine. The Comprehensive Textbook of Healthcare Simulation: Springer; 2013; p: 315-28. http://dx.doi.org/10.1007/978-1-4614-5993-4_20

Published by Sciedu Press 
[19] Tien G, Atkins MS, Zheng B, Swindells C. Measuring situation awareness of surgeons in laparoscopic training. Proceedings of the 2010 Symposium on Eye-Tracking Research \& Applications: ACM; 2010; p: 149-52.

[20] Chetwood AS, Kwok KW, Sun LW, Mylonas GP, Clark J, Darzi A, et al. Collaborative eye tracking: a potential training tool in laparoscopic surgery. Surg Endosc. 2012; 26: 2003-9. PMid: 22258302. http://dx.doi.org/10.1007/s00464-011-2143-x

[21] Law B, Atkins MS, Kirkpatrick AE, Lomax AJ, Mackenzie CL. Eye Gaze Patterns Differentiate Novice and Experts in a Virtual Laparoscopic Surgery Training Environment Proceedings of the 2004 symposium on Eye tracking research \& applications. 2004; 41-8.

[22] Wright MC, Taekman JM, Endsley MR. Objective measures of situation awareness in a simulated medical environment. Quality and Safety in Health Care. 2004; 13.suppl 1: i65-i71. PMid: 15465958. http://dx.doi.org/10.1136/qshc.2004.009951

[23] Drews FA, Bakdash JZ. Simulation Training in Health Care. Reviews of Human Factors and Ergonomics, 2013: 8(1): 191-234. http://dx.doi.org/10.1177/1557234X13492977 